problems". An example is image processing where one tries to reconstruct the original and not just any acceptable optimal solution or image. One of the most spectacular applications is the interpretation of seismic data by Rothman [6]. He was able to reconstruct the geological structure of a terrain from information on the propagation of sound waves. Other impressive applications involve the reconstruction of three-dimensional objects from two-dimensional images in tomography, and the deblurring of binary images.

\section{Conclusion}

Simulated annealing offers a rather general approach to time-consuming problems. This is on the one hand its strength but on the other hand also its weakness. That means problem-oriented heuristic approaches may exist which are hard to beat. The general rule seems to be: the more money at stake in the solution of a particular problem, the better is the existing heuristics. This is certainly the case in chip design, where a general breakthrough for simulated an- nealing has not happened so far. But further research aims at this goal [4]. For a huge variety of less popular problems, simulated annealing is the way to proceed. In such a case, I encourage the reader to try my recipe. If the problem turns out to be "spin-glass-like", a comparatively good solution can be obtained for an optimal state. The future of simulated annealing certainly lies in the large variety of such problems waiting to be discovered in all branches of science, technology and economics.

\section{REFERENCES}

1. Kirkpatrick S., Gelatt C.D. and Vecchi M.P., Science 220 (1983) 671.

2. "Heidelberg Colloquium on Spin-Glasses", in Lecture Notes in Physics 192, eds. J.L. van Hemmen and I. Morgenstern (Springer-Verlag, Heidelberg) 1983.

3. Binder K. and Young A.P., Rev. Mod. Phys. 58 (1986) 801.

4. "Heidelberg Colloquium on Glassy Dynamics", in Lecture Notes in Physics 275, eds. J.L. van Hemmen and I. Morgenstern (Springer-Verlag, Heidelberg) 1987.

5. Grest G.S., Soukoulis C.M. and Levin K., Phys. Rev. Lett. 56 (1986) 1148.

6. Rothman D., Geophysics 50 (1985) 2784.

\section{SOUIDS}

Continuing the series of Workshops especially conceived to interest our Associate Members, will be one on the "SOUID: State of the Art, Perspectives and Applications". It will be held at the CNR headquarters in Rome from 22-24 June 1988 . Over $2 \frac{1}{2}$ days the Workshop will be discussing current developments and will also consider the impact of the new oxide superconductors.

Organising the Workshop are Profs. P. Carelli of the University of Aquila and A. Paoletti of the CNR together with the EPS Secretariat. A maximum number of 50 participants is envisaged including nine review speakers. Dead-line for returning Pre-registration forms (available at the Secretariat) is 29 February 1988. Invitations will be sent out in April. No proceedings are planned, but some papers will be available at the time.

Staff members of EPS Associate Members and IOMs will be charged Sw.Fr. 200.-; all others Sw.Fr. 400.-, although invited speakers from Universities may apply for a reduction.

\section{CATEGORY 4a)}

M. Al-Bakir, Baghdad, Iraq

E. Canessa, Norwich, UK

Ch. Chang, Berlin W.

D.G. Gratias, Vitry, F

T.T. Luong, Caen, F

\section{CATEGORY 4c)}

Danish Physical Society

K. Dyrbye, Aarhus

J. Mygind, Longby

I. Shim, Ballerup

Eötvös Lorand Physical Society

L. Koltai, Budapest

I. Vomberg, Budapest

Finnish Physical Society

S.S.H. Kasi, Kerava

\title{
New Members of the European Physical Society
}

German Physical Society

Walter Buckel, Karlsruhe

R. Kalla, Münster

S. Martin, Murray Hill, NJ, USA

W.F. Staudt, Kaiserslautern

T.A. Vilgis, Mainz

W.F. Wreszinski, Sao Paulo, Brazil

Hellenic Physical Society

G. Brodimas, Patras

\section{The Institute of Physics}

C.M.C. de Castilho,

Salvador-Bahia, Brazil

D. Evans, Durham

P.D. Greaves, Copenhagen, DK

S. Holloway, Liverpool

A. Öztarhan, Izmir, TR
Italian Physical Society

U. Amaldi, Geneva, $\mathrm{CH}$

The Netherlands' Physical Society E. de Boer, Nijmegen M.T. Rekveldt, Delft

Physical Section, Union of Czechoslovak Mathematicians and Physicists

J. Mrnustik, Boskovice

Polish Physical Society

J. Kasperczyk, Czestochowa

J.K. Moscicki, Krakow

Romanian National Committee for Physics

G. Constantinescu, Bucharest
Spanish Royal Society of Physics

J. Bausells, Barcelona

A. Criado, Sevilla

J. Marro, Granada

P. Wahnon, Madrid

\section{Swedish Physical Society}

O. Gustavsson, Haninge

Swiss Physical Society

W. Joss, Varces, F

P. Muralt, Balzers, FL

\section{CATEGORY 4d)}

American Physical Society

D.S. Barton, Upton, NY

G. Margaritondo, Stoughton, WI

H. Morawitz, San Jose, CA

Australian Institute of Physics

A.B. Murphy, Garching, D
EPS Divisions, Sections and Group Astronomy and Astrophysics Division Solar Physics Section Atomic and Molecular Physics Division Atomic Spectroscopy Section. Chemical Physics Electronic and Atomic Collisions Molecular Physics Computational Physics Group Condensed Matter Division Liquids Section Low Temperature Physics Section Macromolecular Physics Magnetism Magnetism Metal Physics Semiconductors and insula
Surfaces and Interfaces Surfaces and Interfaces
High Energy \& Particle Physics Division Interdiv, Group on Exptl. Phys. Control Systems Interdiv. Group on Physics for Developmen Nuclear Physics Division Optics Division Plasma Physics Division Quantum Electronics Division
Europhysics News is the official journal of the European Physical Society which comprises 29 National Societies, Academies and Group, about 4000 Individual Members and 75 Associate Members. Governing bodies of EPS are the General Meeting, Council and an elected Executive Committee responsible for detailed policy. EPS promotes the collaboration of physicists policy. EPS promotes the collaboration of physicists throughout Europe, organising and harmonising conferences and publications, improving physics education, ships to sponsored schools in Erice. EPS publishes in addition to Europhys. News, Europhysics Letters (in partnership with national societies), European Journal of Physics (in partnership with The UK Inst. of Phys.). and European Conference Abstracts. Individual Members receive Europhys. News free of charge (price to insts.: Sw.Fr. 90. - /a), Europhys. Lett. at Sw.Fr. 70.-la (insts. 595.-), rebates on many other publications and on conference fees. Annual EPS membership fee for Individual Members belonging to an EPS member society is: Sw.Fr. 44.-; independent members: Sw.Fr. 132.-; members of a Collaborating Society: Sw.Fr. 55.-

\author{
Editor: E.N. Shaw \\ Editorial Board: \\ A. Baratoff, F. James, M. Lehmann, \\ M. Mayor, J. Muller, M. Siegrist \\ Editorial and Advertising Office at the EPS \\ Secretariat \\ Address: EUROPEAN PHYSICAL SOCIETY \\ P.O. Box 69 , \\ CH-1213 Petit-Lancy 2 \\ Switzerland \\ Telephone: Geneva (22) 931130 \\ Telex: 428024 eps ch \\ Cables: europhys genève \\ Printed by: Pfirter frères se \\ $\mathrm{CH}-1213$ Petit-Lancy/Switzerland
}

